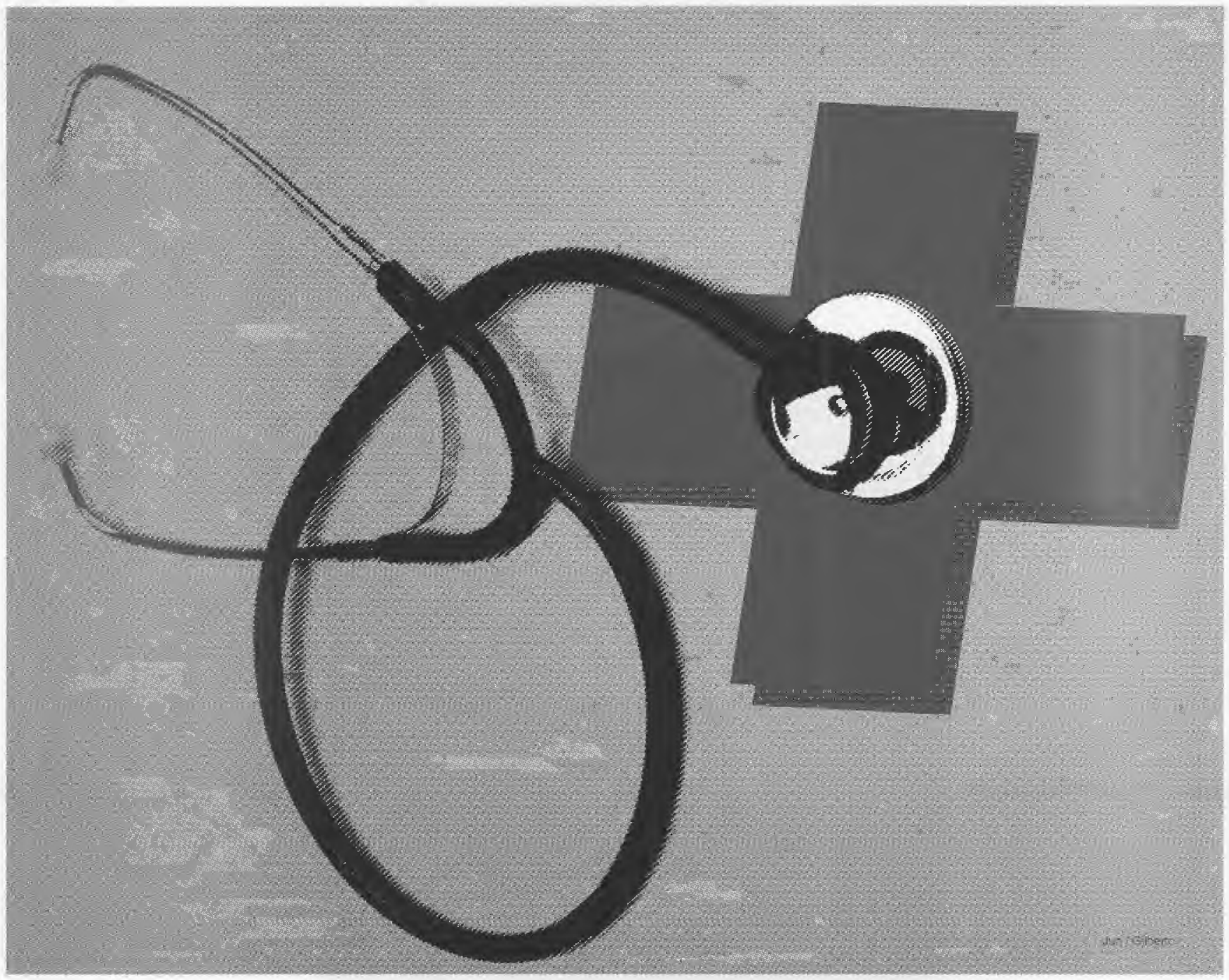

\title{
O DESAFIO DA EQÜIDADE NO SETOR SAÚDE*
}

Elio Jardanovski

Administrador Público e Mestrando em Administraçāo Pública na EAESP/FGV, Técnico da Fundação do Desenvolvimento Administrativo (FUNDAP).

\section{Paulo Cesar Vaz Guimarães}

Economista pela Universidade de Brasília (UNB), Mestrando em Administração Pública na EAESP/FGV e Técnico da FUNDAP.

* RESUM0: Os paises que procuraram construir um sistema público universalizante de saúde depararam-se com o debate sobre a equiidade como principio fundamental de justiça social. O presente artigo discute esta problemática em suas bases teóricas e apresenta, em grandes traços, as caracteristicas essenciais do sistema britânico de saúde e o seu rebatimento nesta questão, visando a subsidiar consideraçōes sobre a realidade brasileira.
PALAVRAS-CHAVE: Eqüidade, Sistema Público de Saúde, Economia da Saúde, Justiça Social.

* ABSTRACT: The countries that looked for an universal public health system had to face the debate of the equity as a fundamental principle of social justice. This paper analyses the theoretical basis of equitu, stressing the British Nacional Health Service characteristics, concerning mainly to equity, to subsidize the analysis of the Brazilian reality.

* KEY WORDS: Equity, Public Health Sistem, The Economics of Health, Social Justice.

* Este texto tem por base a pesquisa "Transferências intergovernamentais de recursos da União para o sefor saúde: a questão da eaüidade" realizada no âmbito da FUNDAP sob a coordenaçāo de Luciano A. Prates Junqueira, contando com a colaboração de Paulo Eduardo Castro Reis. 


\section{INTRODUÇÃO}

A instituição do Sistema Único de Saúde pela Constituição Federal de 1988 definiu a revisão da lógica do modelo dé prestação dos serviços de saúde. Cabe destacar o princípio de universalização do atendimento - a despeito de classe social, localização geográfica, raça, renda, sexo ou qualquer outra forma de categorização das pessoas - que pretende traduzir um tratamento mais eqüitativo dos cidadãos.

Para fazer frente a essa nova realidade, o poder público procura reorganizar-se para garantir recursos em todo o território nacional, sejam eles de caráter técnico, político, financeiro ou organizacional. Um dos mecanismos selecionados para a consecuçāo do objetivo encontra-se na transferência de recursos orçamentários da União para as outras esferas de governo, de maneira a viabilizar a atenção à saúde.

As características manifestas da política acarretam a lembrança do sistema de saúde inglês, que tem sido estruturado, desde o pós-guerra, de forma a atender indiscriminadamente os seus cidadãos. Apesar dos percalços deste sistema, é inegável que ele representa um paradigma para modelos de saúde de outros países. Sua menção é feita, principalmente, em relação à equiidade no tratamento dos usuários do sistema de saúde.

Ao que tudo indica, o legislador brasileiro tinha em mente a intenção de propiciar ao cidadão um serviço com características e objetivos similarcs. Até o presente momento, infelizmente, a falta de regulamentaçăo não esclareceu o que realmente se entende por eqüidade, para daí discernir o que se pretende. Com tais lacunas, o poder executivo tem atuado de forma errática, dificultando a compreensão da direção e objetivos específicos da política de saúde.

Com os resultados que estão sendo delineados, associados à questão da privatização no setor saúde, o que se indaga é se o sistema brasileiro não está caminhando mais no sentido do modelo americano, onde as características - prestação direta pública marginal, benefícios com base nas contribuições ao seguro saúde privado etc. - são antípodas do sistema inglês.
As conclusões de Faveret e Oliveira ${ }^{3}$ reforçam o entendimento de que há contradições entre as intenções expressas na Constituição e a implementação da política de saúde. No contexto das críticas, as condições de exclusão que grande parcela da população poderá vir a sofrer são muito reiteradas, uma vez que não conseguiria acessar o subsistema privado. Por detrás da argumentação, o que se verifica, em síntese, é a preocupação com a vigência das regras de mercado para uma política social em uma realidade notoriamente degradada.

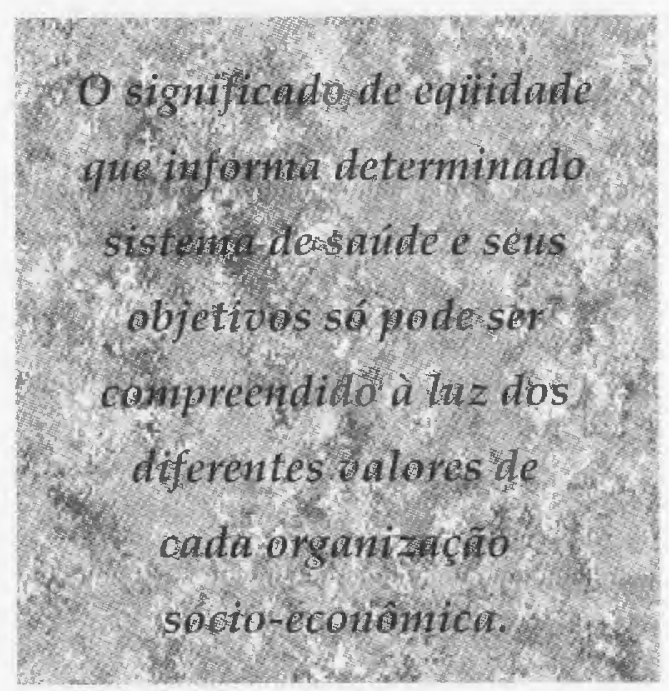

Em contraposição, a corrente que nega a "americanização" do setor saúde defende a participação pública na oferta dos serviços, procurando proporcionar a universalização do atendimento, até como mecanismo de salvaguarda dos direitos do cidadão.

A necessária reflexão que se coloca face a este quadro implica a problematização do arcabouço teórico - conceitos, pressupostos, ideologia etc. - que informa correntes de pensamento que analisam a temática da eqüidade, verificando possíveis desdobramentos para a realidade brasileira.

O presente trabalho discute em primeiro lugar a questão da eqüidade, posto que perfaz o eixo da disputa teórica. Em seguida, apresenta-se, em grandes traços, as características essenciais dos sistemas inglês e o seu rebatimento na problemática da eqüidade, pretendendo subsidiar considerações para a realidade nacional.
1. FAVERET, $P$.; OLIVEIRA, $P$ "A universalização excludente: reflexōes sobre as tendências do sistema de saúde". Planejamento e Políticas Públicas, n.1. 1990, p. 139-162 


\section{SISTEMAS DE SAÚDE E EQÜIDADE}

O significado de eqüidade tem sido freqüentemente associado ao conceito de justiça social. Sua definição e os princípios distributivos daí decorrentes, dependem do conjunto de valores predominante nesta sociedade. Desta maneira, o significado de eqüidade que informa determinado sistema de saúde e seus objetivos só pode ser compreendido à luz dos diferentes valores de cada organização sócioeconômica e, conseqüentemente, da definição que se coloca sobre o conceito de justiça social.

Alguns autores ${ }^{2}$ procuraram verificar as implicações na concepção e estruturação dos sistemas de saúde a partir de algumas realidades sociais. A despeito das diferenças de abordagens, pode-se inferir a existência de duas categorias, representando opções extremas de organização sócio-econômica dentro do modelo capitalista: de um lado, a orientação dita libe$\mathrm{ral} /$ conservadora e, de outro, a social democrática. Cada uma delas irá condicionar, em um primeiro momento, a opção ou não pela eqüidade, e, em segundo plano, a própria concepção de eqüidade a partir das noções de justiça social que elas sugerem.

Para os liberais/conservadores, a liberdade e o individualismo constituem-se valores fundamentais. A liberdade, neste contexto, refere-se à possibilidade dos agentes satisfazerem suas demandas através do mercado; qualquer outro caminho, notadamente através da interveniência do poder público, acarretaria distorção na alocação de recursos e feriria os princípios e valores da sociedade.

Como corolário, tem-se que os resultados nas condições de saúde da população, inclusive em termos de eqüidade, não estariam incluídos no rol de preocupações governamentais. Antes sim, os indivíduos é que seriam capazes e responsáveis para exercer a sua soberania enquanto consumidores, realizando escolhas segundo suas racionalidades, preferências e necessidades. Caso não atinjam uma condição de saúde favorável, também seriam, exclusivamente, os responsáveis pela situação.

A vertente social democrática tem em seu cerne, pelo contrário, a valorização da noção de igualdade, sendo tal manifesta na real possibilidade dos agentes efetivarem as suas opções. Em outros termos, as diferenças individuais - econômicas e sociais - não podem ser condicionantes para o consumo dos bens e serviços de saúde; portanto, todo aquele que necessitar de atenção à saúde para modificar uma situação adversa à sua reprodução social, deverá ter direito assegurado para superá-la.

Tendo presente que a existência de um mercado puro não se encontra em nenhuma realidade concreta, seja no presente ou em períodos passados, na visão social democrata a única maneira de promoção de condições mais igualitárias de oportunidades de consumo de bens e serviços se daria através da intervenção estatal buscando a eqüidade.

Existindo a opção pela eqüidade, coloca-se a questão de como conceituá-la, visto não haver consenso em torno do seu entendimento. Embora seja muitas vezes definida em termos de "igualdade", não equivale necessariamente a tal atributo. Mooney ${ }^{3}$ sugere seis possíveis definições de eqüidade em saúde:

1. igualdade de gasto per capita;

2. igualdade de insumos (recursos humanos, equipamentos etc.) per capita;

3. igualdade de insumos por necessidades iguais;

4. igualdade de acesso por necessidades iguais;

5. igualdade de utilização por necessidades iguais;

6. igualdade de necessidade marginal.

A distinção entre gastos e insumos per capita se faz necessária em função da variação nos preços dos recursos humanos, equipamentos, medicamentos, recursos organizacionais etc., incorporados na prestação de cuidados de saúde, entre duas áreas diferentes de um país. Como resultado, um mesmo nível de gastos poderia comprar mais insumos em uma localidade do que em outra, o que denotaria, nestas situações, o privilegiamento de uma em relação às demais.

Igualdade de insumos por necessidades iguais reflete uma noção mais apurada de eqüidade à medida que, ao invés de simplesmente distribuir igualitaria- 
mente insumos por indivíduos, diferencia-os segundo suas necessidades de saúde. ${ }^{4}$ Essa definição deve pressupor năo só o sentido restrito da quantidade de recursos materiais e humanos (leitos, consultórios, médicos, enfermeiros etc.) por necessidades, mas também a noção mais ampla da qualidade dos serviços oferecidos.

A teoria, entretanto, ainda não foi capaz de definir o que viria a ser de fato a necessidade por cuidados de saúde. ${ }^{5} \mathrm{O}$ único ponto acordado é que esta tem seus contornos estabelecidos, em primeira instância, pelo delineamento e monitoramento do perfil epidemiológico e, em última instância, na relação médico/paciente, com a soberania do primeiro.

O conceito de necessidade não se confunde com o de demanda, estando afeto a algumas características técnicas (método diagnóstico, procedimentos terapêuticos, epidemiologia etc.) e não ao mapa de preferências do consumidor, ou seja, opiniões ou desejos, especialmente em função do sofrimento, do que este acha que deveria ser passível ou não de tratamento médico. Desse modo, nem todas as demandas se converterão em necessidades e, de outro lado, nem todas as necessidades percebidas institucionalmente se concretizarão como demandas.

A demanda por serviços de saúde, por sua vez, é influenciada por fatores suplementares, como o nível educacional. Não bastam, por exemplo, garantias de distribuição espacial equilibrada dos recursos por necessidades. Tais requisitos, embora necessários, não são suficientes, pois nem sempre asseguram o uso eqüitativo dos serviços. Pessoas melhor informadas usam de forma mais adequada, e com mais freqüência, os serviços de saúde. Aspectos culturais e até religiosos podem ter influência decisiva. Nesse sentido, Titmuss $^{6}$, no final da década de 60 , já havia demonstrado que os grupos de renda mais alta e melhor nível educacional faziam melhor uso dos serviços públicos de saúde.

Isto remete aos conceitos de igualdadc de acesso e utilização por necessidades, onde o primeiro está relacionado fundamentalmente com o lado da oferta de serviços ou cuidados ${ }^{7}$, e o segundo é uma função tanto da oferta como da demanda de saúde. Em outras palavras, igual acesso significa que dois ou mais indivíduos incorrem nos mesmos custos para acessar um determinado serviço de saúde, por exemplo moram a uma mesma distância do serviço oferecido e usufruem da mesma facilidade de transporte para acessálo. Se vão usá-lo de forma igualitária, uma vez garantido o acesso eqüitativo, dependerá da valoração que fizerem do uso destes serviços e de sua real condição de saúde.

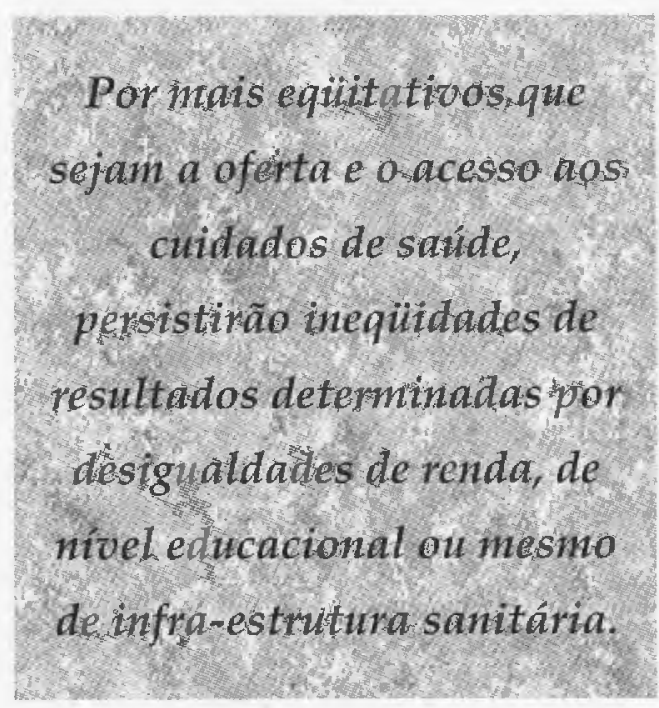

Deste modo, a composição entre diferentes níveis de acesso e demanda vai resultar no nível efetivo de utilização por iguais necessidades, sendo que ocorrerá utilização igualitária dos serviços pelos usuários quando as facilidades (ou dificuldades) de acesso pelos indivíduos forem iguais e quando as demandas pelos respectivos serviços por indivíduos forem também as mesmas.

A qualidade dos serviços é outro fator que influencia a demanda. Do ponto de vista do usuário, a qualidade percebida contribui para aumentar a procura ou, inversamente, desestimulá-la, constituindo-se forte elemento para a eqüidade (ou inequiidade) na utilização dos cuidados de saúde.

A "Lei de Atenção Inversa", formulada por Hart no início dos anos 70, preconizava que a disponibilidade de bons cuidados médicos tende a variar inversamente à necessidade da população servi$\mathrm{da}$, evidenciando que a oferta de qualidade se ajustava mais fortemente às caracte-
4. Necessidade não deve ser assumida enquanto um fenômeno deterministico, já que sempre se estará mencionando uma probabilidade de ocorrência de doenças. Ver MUSGROVE, P. "La equidad del sistema de servicios de salud: conceptos, indicadores e interpretacion". Boletín de La Oficina Sanitaria Panamericana, $\pi .95,1983$, p.525546; ___ _Measurement of equity in health". Worlo Health Statistics Quarterly, п.39, 1986, 325-335.

\section{MOONEY, G. Op, cit.}

6. VIANNA, S. "Eqüidade nos serviços de saúde". Texto para discussão nำ 4, Brasilia: IPEA, 1989.

7. DANIELS, N. "Equity of access to health care: some conceptual and ethical issues". Mirbank Memorial Fund Quarterly, ก. $60,1982,51-81$. 


\section{Idem, ibidem}

9. Vale lembrar que a oferta de serviços de saúde, no sistema capitalista, é também influenciada por aspectos outros que as condições de saúde (por exemplo, tecnologia, monopólio da indústria farmacêutica etc.) acabando por condicionar a própria demanda.

10. Os conceitos de gastos per capita e insumos per capita não consideram o problema das necessidades, não se aplicando a análise vertical de equiidade.

11. Salienta-se que, teoricamente, a igualdade de acesso não é totalmente imprescindivel para a eqüidade de utilização. E factível crer que indivíduos em diferentes condições de acesso aos serviços de saúde, poderiam usufrui-los igualitariamente segundo suas necessidades. Logicamente, estariam presentes esforços distintos para acessálos. rísticas sócio-culturais da demanda do que às suas reais necessidades. ${ }^{8} \mathrm{Em}$ outras palavras, quer-se dizer que a oferta de serviços de qualidade não é unicamente uma decorrência das definições da política de um sistema de saúde, mas também função da pressão de grupos sociais organizados. ${ }^{9}$

Dessa forma, o que se pode deduzir da Lei de Hart é que o poder de pressão de grupos de usuários dos serviços de saúde tende a variar inversamente às suas respectivas necessidades. Como resultado, ter-se-á grandes probabilidades de ineqüidade de utilização nos cuidados de saúde.

A eqüidade de necessidades marginais está baseada na abordagem de custo-benefício. Esta corrente teórica parte do princípio de que uma autoridade de saúde vai alocar racionalmente recursos escassos por aquelas atividades ou projetos para as quais a razão entre benefícios e custos seja a maior, e continuará a fazê-lo até que tenha sido esgotado todo o orçamento. Terá, portanto, que estabelecer uma hierarquia de necessidades a serem satisfeitas expressas na razão benefício/custo.

Segundo este critério, provavelmente os procedimentos relacionados à saúde coletiva seriam privilegiados, visto que os benefícios repercutiriam por um maior número de pessoas, associados a custos baixos. Naturalmente este é apenas um dos elementos utilizados pelos policy-makers, que ponderariam outras informações.

A análise custo-benefício representa, portanto, uma abordagem capaz de valorar as diversas necessidades de saúde, possibilitando a hierarquização das mesmas pela ótica monetária. Tem-se aqui uma diferença sensível em relação às definições anteriores, visto que, afora uma análise intranecessidades de saúde dos indivíduos, permite uma avaliação internecessidades.

A análise intranecessidade reflete a noção de eqüidade horizontal, onde pretende-se identificar e tratar igualitariamente indivíduos que se encontram em uma necessidade de saúde igual. A dimensão internecessidades, que não é contemplada pelas definições iniciais, denomina-se eqüidade vertical, que busca o tratamento "apropriadamente desigual" de indivíduos em necessidades de saúde distintas.
Não se pode concluir que a questão das prioridades, contemplada na eqüidade internecessidades, não se coloca nas definições de eqüidade a partir de insumos, acesso e utilização por necessidades. ${ }^{10}$ De fato, o que se tem é que na implementação de políticas, que tenham aquelas definições de eqüidade como princípio, as prioridades são dadas exogenamente e não determinadas por qualquer dos conceitos de eqüidade per se.

A despeito do critério adotado, cabe alertar que, não obstante o papel que os serviços de saúde desempenham na redução das desigualdades sociais, constata-se que essas diferenças dependem essencialmente de variáveis exógenas ao sistema de saúde. Em outras palavras, por mais eqüitativos que sejam a oferta $e$ o acesso aos cuidados de saúde, persistirão ineqüidades de resultados determinadas por desigualdades de renda, de nível educacional ou mesmo de infra-estrutura sanitária. Essas variáveis, além de assegurarem por si mesmas melhores condições de vida, contribuem para aumentar o acesso, o uso e até a eficácia dos serviços, mesmo quando proporcionados de forma supostamente eqüitativa.

Em função do exposto, pode-se inferir que o conceito de equiidade de utilização é aquele que reflete uma noção mais completa de eqüidade, pois pressupõe que os outros conceitos já tenham sido contemplados, especialmente a igualdade de insumos e o acesso por necessidades iguais. Ou seja, não se pode pensar no uso eqüitativo dos serviços de saúde por necessidades quando $o$ acesso, em alguma medida, não o é. ${ }^{11}$ Naturalmente, para atingir a eqüidade de utilização, o setor saúde deverá se articular com os demais setores de intervenção pública, uma vez que não dispõe de mecanismos que dêem conta deste objetivo.

Entretanto, existiria, ainda, uma lacuna em relação à avaliação vertical das necessidades que o conceito de eqüidade de utilização não contempla e, teoricamente, a abordagem marginalista o faz. Na realidade, esta desvantagem assinalada não existe pelo fato do cálculo custo-benefício, até o momento, não ter conseguido dar respostas satisfatórias para a mensuração de muitas das variáveis pertinentes. 
Como alternativa factível, acredita-se que o ranking de necessidades deve ser desenhado, em última instância, por um processo político. Este, elencando as prioridades para o setor, subsidiaria a tomada de decisão com relação à alocação dos recursos e insumos buscando, por fim, a igualdade de utilização por iguais necessidades.

A partir dos diversos critérios sobre equiidade, conclui-se que não existe uma única forma de defini-la. Esta vai depender da valoração que se faça sobre a eqüidade em si, bem como em relação aos outros objetivos do sistema de saúde, que são muitas vezes conflitantes.

Um dos aspectos importantes nessa questão diz respeito à inter-relação potencial entre equidade e eficiência. $O$ conflito pode emergir, muito provavelmente, quando se trata da eqüidade vertical - tratamento desigual para os desiguais. Por exemplo, em determinado contexto, reduzir riscos com poucos recursos para a maioria da população poderia salvar menos vidas do que concentrar esses mesmos recursos para poucos de alto risco, deixando sem assistência, portanto, a maioria. $\mathrm{O}$ que se verifica, em suma, é uma decisão a respeito do que corresponderia a uma magnitude ótima para eficiêncía e para eqüidade.

$\mathrm{Na}$ atualidade, encontra-se esta situação, por exemplo, no debate travado sobre estratégias de combate às doenças terminais, das quais destaca-se a AIDS. Pode-se argumentar que a análise da equidade com base nas necessidades marginais (custo-benefício) desaconselhasse a alocação de recursos para esta categoria de doenças. Em contraposição, poderia até sugerir a opção pelo atendimento daquelas morbidades em que a expectativa de sobrevida trouxesse maiores benefícios para o indivíduo $\mathrm{e}$ para a sociedade.

A decisão sobre este tipo de conflito, no entanto, remete para questões de ordem ética, e não à racionalização de variáveis de dimensão econômica. A resposta, em última análise, encontra-se nas opções ideológicas que cada sociedade, inexoravelmente, deve realizar ao definir seu sistema de saúde com suas prioridades.
Neste contexto, o Sistema Nacional de Saúde inglês fornece um exemplo interessante na condução da problemática da eqüidade. A incorporação da noção de "direito à saúde" dos cidadãos, independentemente de qualquer condição prévia, já evidenciava uma opção ideológica que tinha como mote principal a distribuição centralizada dos cuidados de saúde, através do setor público, visando à eqüidade.

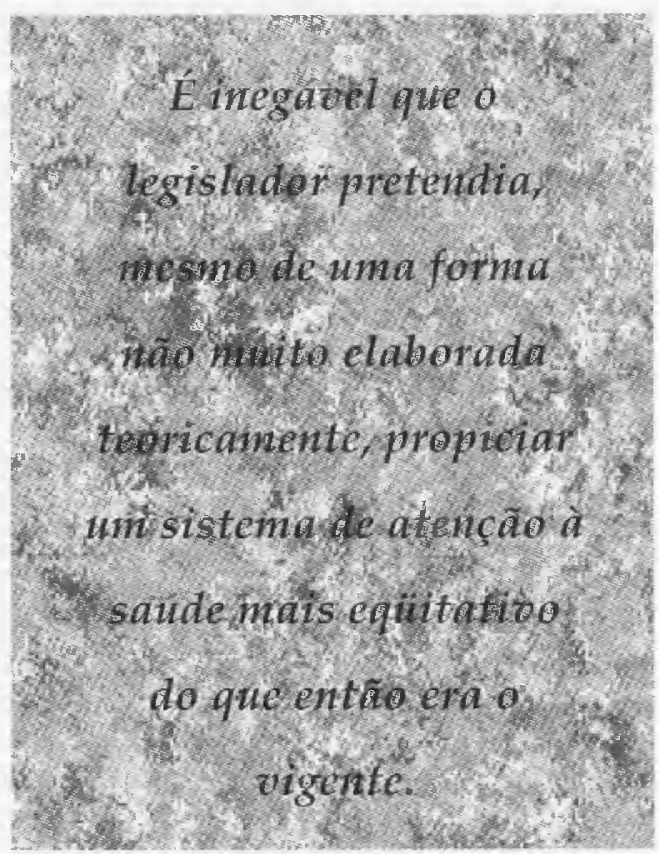

Nos últimos anos, o governo inglês vem revisando o alcance do sistema. Em dado momento, chegou-se à conclusão que o objetivo de equiidade com condições de operacionalização e relativa efetividade relacionava-se à eqüidade de acesso. Como forma de alcançá-la, optou-se pela inserção de um mecanismo de distribuição de recursos financeiros entre regiōes que viabilizasse o acesso igualitário.

O próximo segmento procura justamente recuperar, de forma breve, o histórico do sistema inglês, salientando os aspectos pertinentes à eqüidade e às mudanças que estão se configurando na atualidade, onde o cerne da questão gira em torno do conflito eqüidade e eficiência. A depender do vetor resultante, poder-se-á, inclusive, deslocar os valores basilares que nortearam as reformas do pós-guerra. 


\section{A INTERVENÇÃO ESTATAL EM SAÚDE: O CASO INGLESS}

\section{Origem do National Health Service (NHS)}

A instituição do Sistema Nacional de Saúde na Inglaterra, em 1946, está intimamente relacionada com o descontentamento popular, e mesmo da classe médica, com o sistema até então vigente. Uma das explicações para o agravamento da situação consiste, indubitavelmente, nos impactos gerados pela Segunda Guerra Mundial, sejam aqueles vinculados diretamente ao setor saúde ou os de âmbito externo, que pressionavam a revisão das relações Estado/Sociedade. ${ }^{12}$

A explicitação mais marcante deste cenário foi a substituição do partido hegemônico no Parlamento, quando da ascensão do Labour Party. Como repercussão imediata, houve alterações nas prioridades da agenda política, passando a prevalecer iniciativas para fortalecer o próprio Estado do Bem-Estar. Neste intento, contou-se com fortes lideranças políticas que empreenderam esforços no sentido de aprovar um vigoroso sistema público de saúde, inclusive negociando diretamente com a classe médica, opositora "natural" da proposta. Cabe a indagação, portanto, sobre quais foram as motivações para a introdução do NHS.

Ao enfocar explicitamente a questão, Mooney ${ }^{13}$ fornece um quadro da intensa controvérsia criada em torno do tema, debatendo as contribuições de Lees, Culyer e Titmuss. $O$ primeiro argumentava, ainda na década de 60 , que o principal objetivo do NHS era incrementar o consumo dos produtos da atenção médica, visto que o padrão distributivo até então era acentuadamente desigual. Assim, consistiria passo fundamental a retirada do primado do preço (regras de mercado) enquanto mecanismo para a alocação de recursos. Em outras palavras, melhor seria que "o rol de preferências fosse elaborado centralizadamente, e então aplicado uniformemente em todo o pais."

Para Culyer, dado um mix de produtos a ser ofertado e uma escala de prioridades, o sistema público seria mais eficiente do que algum tipo de subsídio ou instrumento semelhante. Isso decorre, em parte, do pressuposto de que os valores en- contrados na comunidade são relativamente homogêneos, facilitando o discernimento sobre preferências.

Além disso, este autor é da opinião de que a prestação do serviço público consiste em uma forma das pessoas repassarem a responsabilidade da atenção à saúde da esfera privada para a pública, tendo em vista as externalidades trazidas por condições inadequadas de saúde. Como os sistemas calcados no mercado não levam em consideração os custos sociais advindos da ocorrência de doenças, somente um gestor público terá preocupação com a eqüalização da condição de saúde da população e assim reduzir as externalidades negativas.

Titmuss, por sua vez, vê na instituição do NHS um procedimento que foi capaz de incentivar a reciprocidade e obrigações entre as pessoas. Ou seja, a sua argumentação está essencialmente calcada no problema ético das organizações sociais, e em particular do altruísmo, a fim de que o espectro das condições de saúde pelos estratos da população não sejam tão desiguais.

Nenhuma das posições, contudo, deu conta, integralmente, do que informou a criação do NHS, pois cada um dos três autores privilegia parte do problema. De qualquer maneira, embora algumas análises alertem para inconsistências e dubiedades na formulação inicial do NHS, é inegável que o legislador pretendia, mesmo de uma forma não muito elaborada teoricamente, propiciar um sistema de atenção à saúde mais eqüitativo do que então era o vigente.

\section{Características do NHS}

A conformação assumida ao longo dos anos transformou muitas das características iniciais do NHS, todavia sem nunca perder de vista o objetivo de fornecer a atenção universal. Aparentemente, ainda que apresentando impactos substanciais, tais alterações parecem ter procurado mais uma adequação do sistema à dinâmica social do que medidas de reformulação.

$\mathrm{Na}$ atualidade, seguindo as indicações de Leichter ${ }^{14}$ e Ham, ${ }^{15}$ o NHS cobre a maioria da população residente na GrãBretanha, a despeito de idade, sexo, ocupação, classe social, raça etc. Para inte-
15. HAM, C. Health policy In Brihers, 1985. 
grar o sistema, o cidadão deve se registrar junto a um médico de familia, que será responsável pelo primeiro contato e, se necessário, o encaminhará para um especialista. Caso exista demanda por SADT (Serviço de Apoio Diagnóstico Terapêutico) ou hospitalização, somente este especialista estará habilitado a fornecer autorização.

Vale salientar que os serviços de atenção primária não são restritos às atividades médicas, incluindo enfermeiros, visitors e assistentes sociais. Este nível de atenção atua em centros de saúde, desenvolvendo em todo território ações de vacinação, pré-natal, prevenção etc. Isso não quer dizer que a cobertura seja perfeita, uma vez que os médicos, por serem autônomos e não empregados, têm a garantia de escolher área de trabalho. Por conseguinte, as possibilidades de planejamento sofrem restrições.

A hospitalização é realizada sem qualquer ônus para o paciente, mesmo para intervenções complexas e de longa duração. A única distinção colocada diz respeito ao tipo de leito, visto que uma pequena taxa é cobrada daqueles que optem por uma modalidade mais "privati$v^{\prime \prime}$. Tal aspecto não significa que os leitos reservados aos particulares se mantenham como no início do sistema; dado os problemas que o esquema implicava privilégios, corrupção etc., foi abandonado em meados dos anos 70 .

Já para os tratamentos dentários, serviços oftalmológicos e produtos farmacêuticos, existe alguma forma de compartilhamento de custos. No primeiro caso, $50 \%$ do encargo é de responsabilidade do usuário, embora não arque com a consulta e esteja estipulado um teto para a sua contribuição. As despesas com consultas oftalmológicas também são integralmente reembolsadas, mas os óculos não. Para os medicamentos há uma taxa, mas que pode ser dispensada para determinadas categorias de paciente, o que também é válido para outros serviços.

Dentre a clientela, aquelas que atraem maior ênfase para o tratamento diferenciado são os idosos, doentes psiquiátricos, gestantes e crianças. Os mecanismos utilizados na diferenciação são múltiplos e guardam estreita relação com seus objetivos; no entanto, possuem alguns traços em comum. Mais explicitamente, as polí- ticas desenhadas para atender as vicissitudes daqueles usuários sublinham a relevância do relacionamento hospital/comunidade/família. Por este caminho, pretende-se alterar a lógica da prestação do serviço no sentido de maior efetividade (leitos especiais, centros de treinamento etc.), além da contenção do custo (serviços locais, hospitais menores etc.)

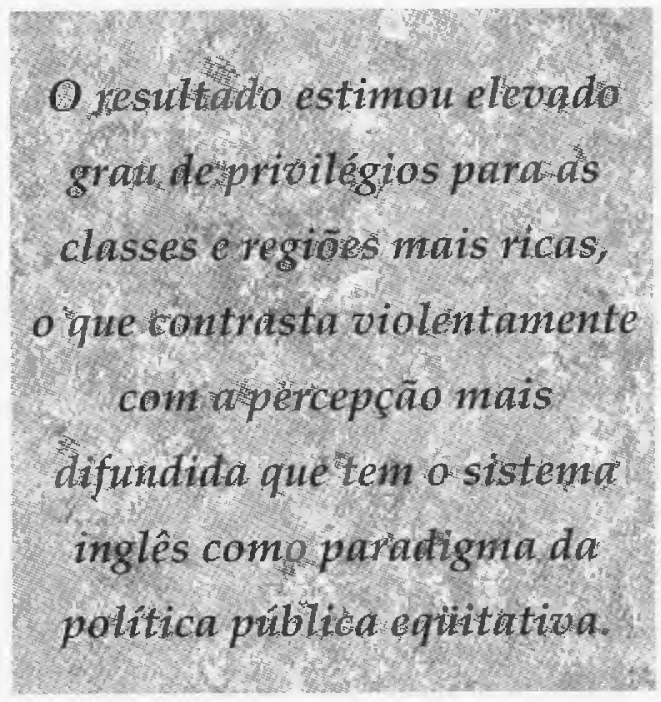

As dificuldades para implementar as políticas ao nível local, por sinal, representam algumas das principais críticas que o NHS recebia alé meados da década de 70. Nessa época, as pressões pela reestruturação impulsionaram a revisão da arquitetura institucional visando: à unificação dos serviços de saúde sob uma só autoridade; à coordenação entre autoridades de saúde e serviços locais; e ao melhor gerenciamento em todos os níveis.

A pós os debates gerados pelas propostas, chegou-se a um desenho que privilegiou as autoridades regionais enquanto planejadores dos serviços de saúde. A prestação propriamente dita ficou a cargo dos distritos de saúde, atuando em estreita relação com os conselhos comunitários. Ao nível central (Departamento de Saúde e Seguridade Social) ficaram vinculados apenas os comitês responsáveis pelo gerenciamento dos contratos com os médicos, mantendo este uma grande autonomia em razão da especificidade de sua função.

Para empreender todas as atividades, o sistema de saúde conta basicamente com os recursos provenientes dos impos- 
16. FENN, P.; MCGUIRE, A. "La reforma del Servicio Nacional de la Salud en el Reino Unido". Revista de economia, n.681$682,1990,0.27-43$; AKERMAN $M$. "As recentes mudanças do sistema de saúde britânico: alvoroco na cidade da Corte". Saúde em Debate, n.34, 1992, p.47-50.

17. TOWNSEND, P.; DAVIDSON, N. Inequalities in health. London: Penguin, 1982

18. TITMUSS,Richard. Commitment of Welfore. London: Allen and Unwin, 1968. Apud HAM, C Op. cit. tos $(90 \%)$ e uma pequena parcela de contribuições especiais e taxas. Um rateio desta natureza permite, a priori, que se alcance a eqüidade no financiamento dos serviços dado que não existe vinculação direta entre estes e o pagamento de tributos.

Na última década, contudo, as evidências levam a acreditar na mudança na composição do "bolo", pois a gestão do partido conservador é simpática à maior participação das taxas. Afora isso, também se advoga o incremento no seguro saúde, onde os benefícios são proporcionais à contribuição, além de outros mecanismos mais característicos de economias de mercado.

A mais recente manifestação da tendência de introdução de mecanismos de mercado ocorreu em 1989, quando anunciou-se as propostas de reformas para a década seguinte. Basicamente, o eixo condutor da proposta está calcado no estímulo à concorrência entre os produtores de bens e serviços de saúde, principalmente através da disputa por pacientes. ${ }^{16}$

Para que tal venha a acontecer, prevêem-se modificações na estrutura de funcionamento, empreendendo-se integração vertical. Esta se dará com a centralização de poderes em um novo órgão gestor (NHS Management Executive), incumbido de supervisionar os serviços hospitalares, sócio-sanitários e os médicos de família. Paralelamente, as instâncias regionais terão concorrentes na figura dos "titulares de orçamento" (budget holders). Estes, para atraírem o maior número de pacientes, necessitarão negociar custos e qualidade com os serviços (hospitais, por exemplo). Assim, o consumidor poderá exercer alguma forma de pressão para garantir a satisfação de sua demanda.

Cumpre indagar se os objetivos serão realmente alcançados ou prevalecerá a atuação de monopólios, como se verifica na atualidade, podendo até elevar os custos. Neste caso, com um agravante adicional, pois o prestador poderá selecionar a sua clientela conforme seus interesses. Além disso, a soberania do consumidor é muito questionável na área da saúde, da$\mathrm{da}$, entre outros fatores, a mística presente na relação médico/paciente.
Conclui-se que as brechas para o incremento de serviços de baixa qualidade, associados à discriminação, serão muitas, requerendo forte regulação por parte do poder público.

\section{Os impactos do NHS}

Um dos estudos com maior abrangência sobre a eqüidade do NHS indiscutivelmente foi o "Relatório Black", constante do trabalho de Townsend e Davidson. ${ }^{17} \mathrm{~A}$ pesquisa procurou detectar as condições de acesso e consumo dos serviços de saúde, verificando a ocorrência ou não de desigualdades em relação a três categorias: geográficas, classes sociais e grupos de clientela. $O$ resultado estimou elevado grau de privilégios para as classes e regióes mais ricas, o que contrasta violentamente com a percepção mais difundida que tem o sistema inglês como paradigma da política pública eqüitativa.

A mensuração dos desníveis encontrados entre as classes sociais utilizou como referencial o comportamento das taxas de mortalidade e morbidade, além do grau de utilização dos recursos. Uma primeira constatação foi relativa ao insucesso do NHS em diminuir as diferenças entre os valores das taxas de mortalidade pertencentes aos extremos superior e inferior desde a sua instalação. Este padrão é verdadeiro para os primeiros períodos de vida (mortalidade perinatal e infantil) e permanece na fase adulta, tanto entre os homens como em mulheres.

No tocante à morbidade, os estudos não conseguiram ser tão precisos em decorrência da precariedade de informações. Não obstante, apontam com relativa firmeza a discrepância entre doenças de longa duração, que prevalecem com mais intensidade nas classes pauperizadas. De qualquer forma, no geral, os indícios são marcantes sobre o maior número de doenças para aqueles com menos afluência.

Quando se considera o problema de uso dos recursos (eqüidade de utilização), verifica-se, desde a década de 60 , que os grupos de renda mais elevada recebem maior atenção dos especialistas (medida, por exemplo, pelo tempo de duração da consulta); usufruem dos hospitais mais bem equipados; dispõem de um atendimento à maternidade melhor; e alcançam mais facilmente os tratamentos psiquiátricos. ${ }^{18}$ 
O que é curioso, ainda, é que o padrão excludente também vale para os serviços de atenção primária. A explicação parece residir no fato de que existem grupos que "dominam" estratégias para acessar os recursos, e quando o fazem recebem mais em relação aos demais.

Assim, no resultado final, conforme aponta Le Grand ${ }^{19}$, as classes inseridas no limite superior detinham $40 \%$ a mais do gasto por pessoa do que aquelas do limite inferior. Para o autor, contribui para tanto o custo proporcionalmente mais elevado que atinge as camadas mais pobres quando necessitam despender tempo para se encaminhar ao serviço, bem como a própria acessibilidade dos serviços que beneficia os altos grupos sociais. O fato principal, no entanto, deve ser procurado mais nas condiçōes materiais de sobrevivência do que nas características intrínsecas do serviço de saúde; ou seja, no quadro geral de distribuição de renda.

Outro tipo de desigualdade discutido no âmbito do NHS foi referente aos desvios entre grupos de clientela, tendo por parâmetro os padrões de atenção médica. Particularmente, concluiu-se que a atenção aos idosos e aos doentes psiquiátricos não apresentavam prioridade significativa na atuação. É certo que diligências foram encaminhadas no sentido de elevar os gastos com estes segmentos que exigem tratamento com taxas de longa permanência, mas ficaram isoladas no tempo. Aparentemente, a dificuldade está em fazer valer as diretrizes centrais na disputa de recursos, já que estes grupos não têm condições de pressāo ao longo do processo de implementação das políticas.

Por fim, a distribuição desigual de recursos entre as regiōes geográficas salienta algumas impropriedades do sistema de saúde britânico. Naturalmente não é pretendido, a priori, o perfeito equilíbrio entre localidades, até porque seria uma premissa injusta que descartaria o papel do perfil regional. Entrettanto, esperava-se que o NHS firmasse um padrão mais eqüitativo, seja medido pelo comportamento na taxa de mortalidade, seja pela alocação de recursos segundo necessidades.
Um motivo que concorre para as desigualdades regionais é que este aspecto não pertencia ao rol de preocupação dos planejadores até a década de 70. De fato, somente com a instalação do Resource Allocation Party (RAWP) procurou-se "reduzir progressivamente, e o mais rápido possivel, as disparidades entre diferentes partes do país em termos de oportunidade de acesso a atenção à saúde para pessoas em igual situação de risco, levando em consideração necessidades de saúde e fatores sociais $e$ ambientais que podem afetar a necessidade de atenção à sauide". ${ }^{20}$

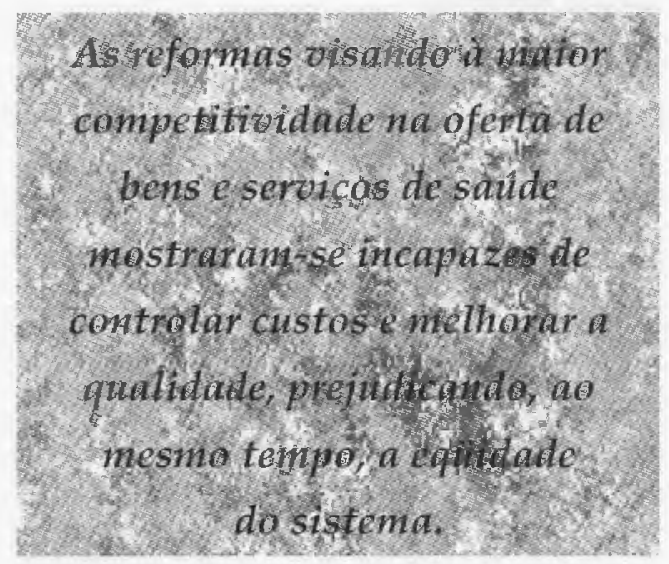

Neste intento, o RAWP seleciona os seguintes critérios: 21

- tamanho da população: ponderação em função do número de habitantes de cada região;

- estrutura populacional: por faixa etária e sexo à medida que esta composição afeta as necessidades relativas;

- morbidade: ponderaçāo em relação à ocorrência relativa de doenças inter-regiões;

- custo: em relação à natureza da morbidade (doenças que demandam tratamentos mais ou menos dispendiosos) e em relaçăo ao preço dos insumos interregiões;

- fluxo inter-regiões: atendimento de pacientes oriundos de outras regiōes administrativas;

- educação médica e dentária: ajustes em função da distribuição desigual de instituiçōes de formaçāo na área da saúde;

- investimentos em capital: ajustes decorrentes não só do estoque de capital, mas também da sua obsolescência e depreciação.
19. LE GRAND, J. The distribution of public expenditure: the case of health core. Econômica. v. 45,1978, p. 125-142. Apud HAM, C. Idem, ibidem.

\section{Idem, ibidem.}

21. MOONEY, G. Op. cit.; HAM, C.Op. cit.; WEST, P. "Theoretical and practical equity in the NHS in England". Social Science and Medicine, n. 15, 1981, p.177-22. 
A operacionalização do RAWP parte inicialmente de uma desagregação dos serviços implementados pelo NHS em sete categorias básicas, com seus respectivos gastos orçamentários médios. Por exemplo, serviços de internação não psiquiátricos (56\% do orçamento global), serviços comunitários $(12 \%)$ etc. ${ }^{22}$ Para cada uma das regiões estima-se as necessidades dos serviços a partir da ponderação dos fatores acima elencados, ajustando os recursos orçamentários dos serviços específicos (categorias) através do desvio padrão destes fatores em relação à média nacional.

Dessa forma, enquanto os fatores indicam o volume global de recursos necessários para cada região, a distribuição segundo as categorias de serviços sublinham as prioridades nacionais definidas pelo Governo Central.

$\mathrm{Na}$ opinião de West ${ }^{23}$, a metodologia elaborada permite satisfazer em grande medida as eqüidades vertical e horizontal, visto tratar as diferenças entre orçamentos, populações, equipamentos, profissionais e custo. Salienta, porém, que estudos futuros sobre características populacionais deveriam propiciar parâmetros mais adequados sobre a morbidade, já que para esta o RAWP faz uso de uma proxy ${ }^{24}$.

Em contraste, outros autores levantam críticas à lógica e à operacionalização da sistemática. Uma primeira advertência recai justamente sobre a pertinência da proxy de morbidade ser derivada de uma medida de mortalidade, dado que não se tem uma posição conclusiva sobre a correlação entre as duas variáveis. Outro problema está na aceitação, sem maiores questionamentos, de que é factível a definição do que seja necessidade de atenção à saúde, assim como a sua mensuração.

Mais importante, porém, é a disjunção entre o planejamento global e a instância de alocação, acarretando a perda das diretrizes da política de saúde. Ham ${ }^{25}$ sublinha a incapacidade da fórmula RAWP adequar-se às mudanças nas prioridades, sejam aquelas decorrentes da arena política ou da própria avaliação dos resultados alcançados.

O que transparece das evidências, contudo, é a relativa ineficácia da siste- mática RAWP em alterar o quadro de desigualdades vigente no início dos anos $80 .{ }^{26}$ Como conseqüência, em substituição ao RAWP, sugeriu-se, no bojo das mencionadas propostas de reformulação de 1989, um esquema baseado no contingente populacional ponderado pela condição de saúde e estrutura etária, mantendo-se a SMR (Standardised Mortality Ratio) como proxy de morbidade. O fato inovador está no reconhecimento da necessidade de algum índice que considere as condições sociais locais intervindo na distribuição dos recursos; infelizmente, o procedimento não foi esclarecido.

Uma outra diferenciação importante advinda daquelas propostas está na instituição dos titulares de orçamento. Neste caso, a sistemática de alocação para despesas com medicamentos e serviços hospitalares obedecerá outros critérios. Em especial, o segundo tipo de serviço utilizará o número de pacientes registrado pelo profissional, referenciado à idade, sexo e condições de saúde (e pelos fatores sociais e locais, sic). Entretanto, ainda é necessário o delineamento mais preciso sobre como a proposta será operacionalizada, verificando os mecanismos que serão criados a fim de evitar a discriminação de clientelas; enquanto isso, é válida a observação de Carr-Hill de que os impactos futuros são obscuros.

\section{CONCLUSÕES E APONTAMENTOS PARA 0 CASO BRASILEIRO}

A estruturação dos modelos de saúde remete à discussão dos princípios norteadores de uma política de saúde. Em última análise, os resultados daí derivados refletirão o matiz ideológico presente em determinada sociedade. Naturalmente não se está afirmando que a configuração será monolítica, mas tão somente que os segmentos sociais necessitarão acordar as bases da política de saúde. A partir destas, encontrar-se-ão negociações ao longo do processo de formulação e implementação.

É neste contexto que a eqüidade constitui uma das preocupações centrais. Uma vez que ela incorpora como valores basais a igualdade e a noção de "direito", pressupõe que os indivíduos devam 
receber cuidados fundamentais - a despeito do critério que se utilize para estabelecê-los - para assegurar suas condiçổes de reprodução social.

$\mathrm{Na}$ área da saúde, a garantia desta condição sugere o discernimento sobre as necessidades de saúde. Exclui-se da avaliação a prevalência de valores e preferências individuais, que caracterizariam modelos calcados em princípios liberais que privilegiam a demanda, independente dos condicionantes de ordem macrossocial.

Se, por um lado, o conceito de necessidade assume primazia, por outro a sua mensuração envolve obstáculos teóricometodológicos ainda não resolvidos a contento. A superação dessa dificuldade, na prática, tem se dado através do delineamento do perfil epidemiológico. Neste aspecto, necessidade não se confunde com demanda, visto que o consumidor não tem o arbítrio para estipular o diagnóstico e procedimentos que atendam sua condição percebida de saúde.

Das várias formas de se definir eqüidade segundo as necessidades de cuidados de saúde dos indivíduos, considerase que a igualdade de utilização por iguais necessidades revela-se, em princípio, como tratamento mais igualitário e justo. Além de contemplar definições mais básicas como acesso, a eqüidade de utilização pressupõe que os benefícios advindos do uso dos serviços ofertados estejam em estreita correlação com as necessidades diagnosticadas ao nível institucional. Paralelamente, pressupõe que a eqüidade internecessidades é definida pelo estabelecimento de prioridades através do processo de negociação política entre setores da sociedade.

Ao assumir explicitamente que as opções deverão ser debatidas em uma arena democrática, minimiza-se a influência que grupos atuantes pelo lado da oferta de bens e serviços exercem no sistema de saúde. Isso porque, ao deixar de confor mar diretamente o padrão do consumidor individual (via tecnologia, propagandid etc.), us interesses aí presentes deverão se manifestar perante outros atores institucionais, com mais poder e informações para se contraporem.

Não deve ser esquecido, porém, que para a eqüidade de utilização vingar, é praticamente vital que outros conceitos de eqüidade tenham sido observados. Ademais, nem esta condição é suficiente, dado que o setor saúde, para proporcionar a eqüidade de utilização plena, deve também articular-se com outros setores sociais.

Entretanto, será necessário reconhecer, até por uma questão estratégica, que outras situações de equỉidade mais exeqüíveis no tempo devam ser alcançadas primeiramente.

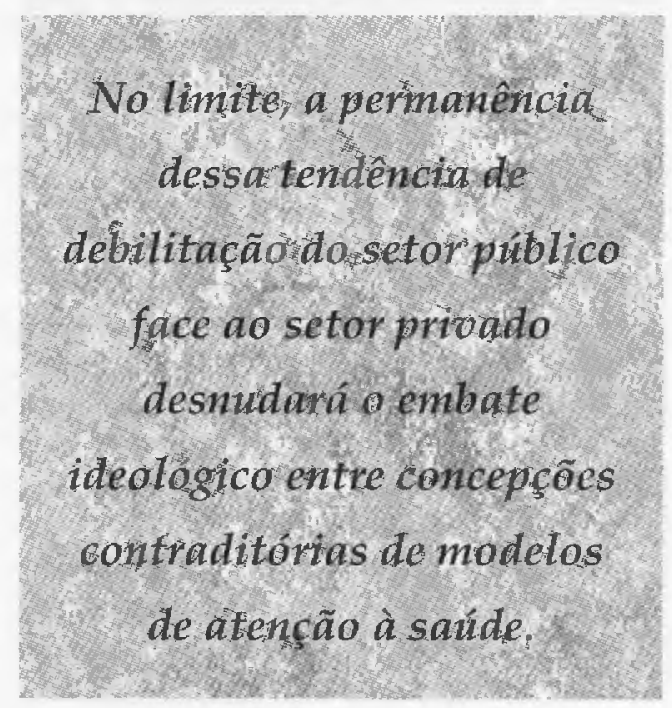

Um exemplo dessa postura encontrase no NHS britânico, onde a distribuição de recursos segundo a sistemática do RAWP espelha a tentativa de obtenção da eqüidade de acesso. Não obstante os avanços alcançados, as próprias autoridades inglesas admitem ainda a permanência de um quadro de desigualdades nas condições de saúde. Conclui-se que a mudança mais radical só teria sido possível com alterações significativas nas variáveis sócio-econômicas, que extrapolam o âmbito do setor saúde.

Este não parece o caminho a ser seguido nos próximos anos, lembrando que as recentes propostas de reforma atentam exclusivamente para o interior do setor saúde. Como agravante, o teor das medidas propugnadas restringem-se aos aspectos de eficiência, evidenciando uma sensível mudança de eixo em relação à eqüidade.

As expectativas com o cenário futuro são até mais preocupantes, tendo em mente a experiência norte-americana. As 
27. HIGGINS, W. "Myths of competitive reform". Health $\mathrm{Ca}$ re Maragement Review, n.16, 1991, p.65-72.

28. Para uma discussão detaIhada sobre a Lei no 8080 e normatizacốes posteriores, consultar FUNDAP. Financiamento do setor saúde: apontamentos sobre a questão das transferências intergovernamentais de recursos da seguridade social. São Paulo: FUNDAP, 1992

29. A saber: 1- perfil demográfico da região; Il- perfil epidemiológico da população a ser coberta; III- características quantitativas e qualitativas da rede de saúde na área; IV- desempenho técnico, econômico e financeiro no período anterior; $V$ - níveis de participação do setor saúde nos orçamentos estaduais e municipais; VI- previsão no plano qüinqüenal de investimentos da rede; VII- ressarcimento do atendimento a serviços prestados para outras esferas de governo; VIII- população proporcional. reformas visando à maior competitividade na oferta de bens e serviços de saúde mostraram-se incapazes de controlar custos e melhorar a qualidade, prejudicando, ao mesmo tempo, a eqüidade do sistema. ${ }^{27}$

No Brasil, as transformações que estão ocorrendo no modelo de saúde também acarretam alterações nas características da oferta de serviços para a população. Isso porque o padrão de distribuição de insumos (equipamentos, recursos humanos etc.), associada a uma distribuição desigual da renda, compromete a eficácia e eficiência da política de saúde no alcance efetivo de maior justiça social.

A dificuldade atual de reverter esse quadro distorcido na localização espacial dos insumos remete ao perfil das políticas de saúde no passado recente. Verifica-se a concentração dos investimentos e recursos em geral nas áreas mais afluentes e com maior renda per capita, em detrimento de regiões mais degradadas socialmente.

Portanto, observa-se a ocorrência de ineqüidades segundo a ótica das várias categorias apresentadas ao longo do texto. Tal se dá desde os aspectos menos complexos - como igualdade de gastos per capita ou de insumos por necessidade - até as noções mais elaboradas, como igualdade de acesso e utilização e necessidades marginais.

A preocupação com esta dimensão se faz hoje presente em razão das disposições elencadas pela Lei Orgânica da Saúde e pela legislação complementar, que preconizam a transferência intergovernamental de recursos (Lei $\mathrm{n}^{\circ} 8.080$, de setembro de 1990, Lei $\mathrm{n}^{\circ} 8.142$, de 28 de dezembro de 1990, e Norma Operacional Básica (NOB) $\mathrm{n}^{0} 01$ do INAMPS, editada pelas Resoluções $n^{0} 258$ e 273). ${ }^{28}$

A Lei $n^{\circ} 8.080$, em seu artigo $35^{29}$, ao apresentar a composição de critérios para transferência, não permite vislumbrar qual o resultado final da repartição dos recursos da seguridade social para estados e municípios. Idealmente, o objetivo almejado deveria atentar para um quadro caracterizado pela justiça distributiva. Para tanto, algum conceito de eqüidade constituiria um princípio a ser adotado para esta repartição, possibili- tando o direcionamento de uma proporção maior de recursos para as regiões com piores condições de saúde, tal qual na sistemática de repartição inglesa (RAWP).

Diante da normatização apresentada pela legislação brasileira, entretanto, é impossível afirmar que tal pressuposto possa ser contemplado em sua essência. Sem dúvida, alguns dos critérios refletem orientações diversas e até conflitantes, como é o caso entre os critérios que mensuram desempenho (financeiro, técnico, qualidade etc.), que tendem a favorecer regiões mais desenvolvidas, e os que procuram medir as condições reais de saúde através do perfil epidemiológico. Neste contexto, fica a questão da pertinência da utilização de critérios eventualmente regressivos, que favoreceriam áreas com menores dificuldades para resolver suas necessidades de saúde.

Além disso, o procedimento que embasa o sistema de cobertura ambulatorial instituído pela NOB no 01 das Resoluções 258 e 273 também se apóia em critérios que trazem resultados que não concorrem para a eqüidade. Haja visto, por exemplo, os itens capacidade instalada e desempenho assistencial que, em tese, nortearam a definição dos valores, através de uma unidade monetária específica para cada região, denominada Unidade de Cobertura Ambulatorial UCA, para a distribuição de recursos para os serviços ambulatoriais.

Toda essa discussão, todavia, fica em grande medida dependente da ponderação que os critérios venham a receber, seja no que diz respeito à fixação da UCA, seja com relação aos critérios do artigo 35 da Lei $n^{2} 8.080$. Isto porque, logicamente, a assunção de pesos diferenciados poderia contrabalançar a preponderância de um resultado eventualmente regressivo, derivado da aplicação de alguns dos critérios, viabilizando uma maior justiça distributiva.

Portanto, os indícios são de que a eqüidade não constitui, de fato, apesar da orientação universalizante, uma diretriz básica do modelo de saúde brasileiro. Isso se evidencia nas transferências de recursos da União que, a nível nacional, ainda representam a principal fonte de financiamento, especialmente para as 
regiões mais pobres. A sua distribuição, ao invés de atender os ditames ponderados pelas necessidades de saúde, responde a critérios casuísticos, delineados segundo pressões de interesses econômicos e políticos.

A conclusão mais embasada sobre as verdadeiras repercussōes relativas à eqüidade ainda não pode ser elaborada. A implementação do modelo de saúde sugere que a eqüidade não está sendo contemplada institucionalmente, estando mais ao sabor das características individuais de cada gerente dos serviços de saúde.

Desta forma, o resultado da política real certamente não reverterá o quadro de desigualdades no setor saúde. Além disso, a crise do Estado brasileiro, com a conseqüente degradação na prestação dos serviços públicos de saúde, tem propiciado, especialmente a partir da última década, a expansão da oferta de modalidades de seguro-saúde privado. Estas acabam por seduzir aqueles segmentos sociais com capacidade de conceber estratégias alternativas a um serviço público ineficaz e de baixa qualidade. ${ }^{30} \mathrm{Se}$ isto, por si só, já representa um forte componente de ineqüidade, fica como agravante o fato dos segmentos remanescentes, dependentes do poder públi$\mathrm{co}$, não possuírem mecanismos de pressão no sentido de garantir o atendimento adequado, em acordo com a linha de argumentação de Titmuss.

No limite, a permanência dessa tendência de debilitação do setor público face ao setor privado desnudará o embate ideológico entre concepçōes contraditórias de modelos de atenção à saúde. Em última análise, ter-se-á que optar pela hegemonia do setor público buscando a universalizaçăo da prestação, conforme defendida pelos grupos que deram suporte ao texto constitucional, ou pelo predomínio das regras de mercado implicando a segmentação da demanda.

A lógica de mercado traz a lembrança do modelo americano de saúde, onde o princípio norteador do desenho das políticas é a liberdade, induzindo a hegemonia do setor privado, sendo portanto a equidade relegada a um plano secundário. Não obstante, mesmo naquela realidade, a premência de uma situação crítica no direito de acesso de classes excluídas do mercado formal de trabalho, forçou a intervenção pública, conquanto de forma residual, no fornecimento de serviços (Medicaid e Medicare) com o objetivo explícito de minimizar as desigualdades.

Cabe a indagação, por fim, de como formular, no Brasil, uma política de saúde que tenha o princípio da liberdade de escolha pelo consumidor através do mecanismo de mercado (preço), quando é notória a violenta concentração de renda em termos pessoais e espaciais.

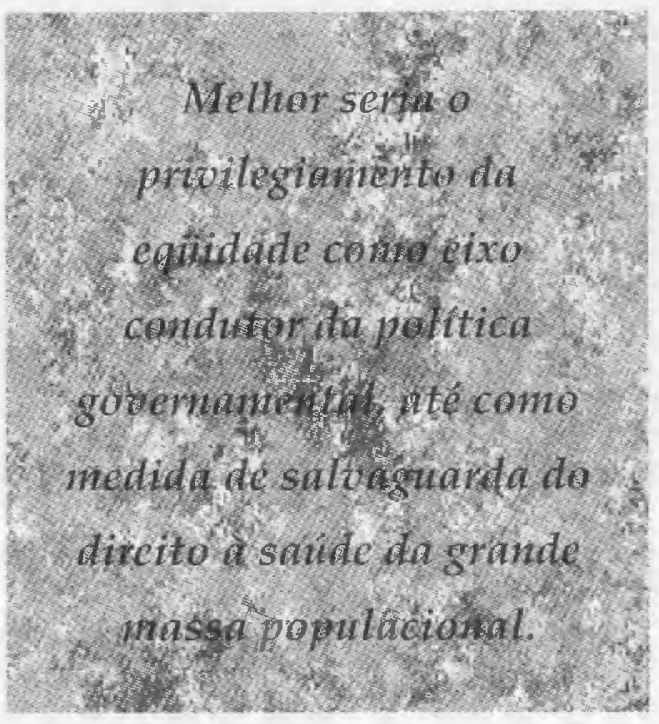

Aqui, melhor seria o privilegiamento da equiidade como eixo condutor da política governamental, até como medida de salvaguarda do direito à saúde da grande massa populacional. É preciso destacar que isto, por si só, não implicaria necessariamente a resoluçāo dos desvios. Como bem ilustra o exemplo britânico, mesmo com a escolha por uma estrutura pública pretensamente universalizante e igualitária, subsistem grandes disparidades no que concerne à eqüiidade de acesso e utilizaçăo dos serviços. Reconhece-se que as razões que dão conta das causas deste quadro encontram-se fora do âmbito das políticas de saúde, mas sim vinculadas ao próprio padrão de distribuição de renda. Nem por isso, ao setor público de saúde fica facultado o direito de não intervir naquilo que the compete para tentar viabilizax a eqüidade.
30. FAVERET, $P_{\text {.; }}$ OLIVEIRA, $P$. Op. cit. 